\title{
The Influences of Lengthening Dimension of Ro-Ro Ferry Toward the Considerations of Hydrodynamics Characteristic and Loading Capacity Aspect
}

\author{
Andi Rachmianty ${ }^{\mathrm{a}}$, Suandar Baso ${ }^{\mathrm{b} *}$, Syamsul Asric ${ }^{\mathrm{c}}$ \\ aDepartment of Naval Architecture, Engineering Faculty, Hasanuddin University. Email: rachmianty@yahoo.co.id \\ ${ }^{b}$ Department of Naval Architecture, Engineering Faculty, Hasanuddin University. Email: andar_baso@yahoo.co.id \\ 'Department of Naval Architecture, Engineering Faculty, Hasanuddin University. Email: sa_tanri_kapal83@yahoo.com
}

\begin{abstract}
The ferry business has become an important business segment for ship designers, builders, and operators. Therefore, many ways have been done in order to increase ferry business through proper design or ship conversion by lengthening the hull. This research is focused on the influences of lengthening a Ro-Ro ferry to hydrodynamics characteristic and loading capacity aspects. 4 (four) ship models are investigated in the present study. The ships are fixed in the same width and draft dimensions. The difference of the Ro-Ro ferries length is indicated by the addition of one column of car space where one column car space is given by car size including the distance between car columns spaces which is an increment of every 5.88 meters. The total resistances of Ro-Ro ferries are obtained by ship model experiment in towing tank. There are 4 ship models that are made. The lengthening of a Ro-Ro ferry is described into non-dimensional parameter by the ratio of ship length and displacement volume $\left(\mathrm{L}^{\prime} \mathrm{V}^{1 / 3}\right)$. The hydrodynamics and the loading capacity of carried car aspects could be described in the ratio of resistance and loading capacity of the carried car $\left(R t / S_{U K}\right)$ with ship speed. The research result shows that the lengthening of a Ro-Ro ferry affects total resistance, speed, and loading capacity of the carried car. The increase of total resistance is caused by higher residual resistance at high speeds and this is experienced by smaller length size ship. Therefore by lengthening the Ro-Ro ferry, it could reduce total resistance at the same speed especially the residuary resistance but eventhough lengthening Ro-Ro ferry the effective speed should be considered. In additions, the effective speed for actual ships dimension in the same $R t / S_{U K} 0.05$ i.e. B5L10 is about 13.85 knot, B5L11 14.33 knot, B5L12 14.94 knot, and B5L13 15.45 knot respectively.
\end{abstract}

Keywords: Hydrodynamics characteristic; loading capacity; ro-ro ferry; ship lengthening

\section{Introduction}

The main dimensions detemine many of the ship characteristics, e.g. stability, hold capacity, power requirements, and even economic efficiency [1]. These ship characteristics are interrelated with each other. The characteristics desired by the shipping company can usually be achieved with various combinations of dimensions. Therefore the main dimensions of a ship should be determined in the preliminary design and then another design stage which is needed to optimize those main dimensions in order to obtain proper design.

There are several types of ship which have a different approach to determine their dimensions. For example, a ferry which is a vessel to carry passengers, cars, and cargo on short sea routes. The ferry business has become an important business segment for ship designers, builders, and operators. In the current situation, the passenger car ferries have been growing in size and

${ }^{\star}$ Corresponding author. Tel.: +62 85255625397

Jl. Poros Malino, Borongloe, Bontomarannu, Kabupaten Gowa, Sulawesi Selatan 92119 capacity. Different with Ro-Ro ferry case, the design concept is focused on Ro-Ro decks for cars, busses, and trucks. Its flexibility, ability to integrate with other transport systems and speed of operation has made it extremely popular on many shipping routes [2]. Then, the problem is the whole design concept that is different from that of traditional ships because of the introduction of a number of elements which make Ro-Ro ships unique. Therefore, the main dimensions of Ro-Ro ferries are important particularly on length and width value to be determined by deck plan consideration.

Researches related to Ro-Ro ferry have been carried out and devoted widely. This paper provides a brief review of that design history and illustrates how that knowledge is applied to new ferry projects. The RoPax concept was improved with high tech solutions where ship functions are divided into two main categories i.e. payload and ship systems, such as payload systems, RoRo decks are arranged for cars [3]. A Ro-Ro ferry design has been optimized by investigation and simulation for hydrodynamics aspects [4]. The numerical, simulation, and safety based design method were described into 
design and building of cruise ferries [5]. The development of a formalized design methodology was facilitated for safer Ro-Ro Ferry by promoting an integrated approach [6]. The multi-objective optimization procedure for the internal compartmentation of Ro-Ro Passenger ships has been formalized [7]. Then, it has been continued where the arrangements of Ro-Ro passenger ships have been optimized with genetic algorithms [8]. The developed optimization procedure could be used both at the conceptual design stage to generate from scratch the internal subdivision of a new design, and at later design stages to improve significantly the survivability of an existing design.

Concurrent with Ro-Ro ferry design research, there were also several studies related to the conversion of the Ro-Ro ferry that had been carried out. A number of ferry conversions were investigated especially their hydrodynamic aspect that has become a trend [9]. The lengthening of an existing vessel is a direct approach for achieving an increased payload. It could add displacement of the existing vessel and increase its stability but it does not automatically mean an increase in the required power. However, the hydrodynamics characteristics are not described and interpreted practically that could be used in design stage. A method for determination of a common transport unit for Ro-Ro passenger ships has been described in mixing cargos, such as passengers, passenger cars, trucks, lorries, busses, and other rolling transport units [10].

Moreover, the demand for transport capacity and ship speed are dependent on service transport demand and traject distance [11]. This research resulted in a model design of Ro-Ro ferry consist of design requirements such as loading capacity and ship speed. The main dimension is estimated base on required loading capacity. The maximum speed is determined to be used for validation with the required speed.

Therefore, this study further analizes the influences of lengthening of Ro-Ro ferry on the consideration of hydrodynamic and loading capacity aspects where the dimensions of width and draft are fixed.

\section{Experimental Set-up}

The model experiment for determining its resistance has been conducted in this research. The ship resistance in this research means water resistance. The towing tank belongs to the Naval Architecture Department, Faculty of Engineering, Hasanuddin University which has a size of $60 \mathrm{~m}$ in length, $4 \mathrm{~m}$ width, and $4 \mathrm{~m}$ depth as shown in Fig. 1. The towing tank is equipped by towing carriage with a maximum speed of $4 \mathrm{~m} / \mathrm{sec}$. Then, it is also equipped by resistance dynamometer R35E as shown in Fig. 2.

There are four Ro-Ro ferries models that were made namely B5L10, B5L11, B5L12, B5L13, and their dimensions are based on actual ship dimensions which are provided by previous research in [11]. Then the body lines plans of the actual ships are shown in Fig. 3. These have a similar geometry with the actual ship and the ships have only different in lenght size. Moreover, the ships also are fixed in the same width and draft dimensions. The difference of the Ro-Ro ferries length is indicated by the addition of one column of car space where one column car space is given by car size including the distance between car column spaces which is about 5.88 meters. The Ro-Ro ferry model is made of wood and fiberglass combination as shown in Fig. 4. The main dimensions of models are determined by using the geometry similarity with scale 1:43 where the actual ship and model dimensions are provided in Table 1 . The dimension of the models considered also the width of the towing tank to avoid blockage effect.

The model speeds have been determined by using kinematic similarity with Froude number $(F n)$ based on the speed of actual ships and were set into five increased speeds i.e. $0.314 \mathrm{~m} / \mathrm{sec}, 0.628 \mathrm{~m} / \mathrm{sec}, 0.942 \mathrm{~m} / \mathrm{sec}, 1.256$ $\mathrm{m} / \mathrm{sec}, 1.570 \mathrm{~m} / \mathrm{sec}$, respectively.

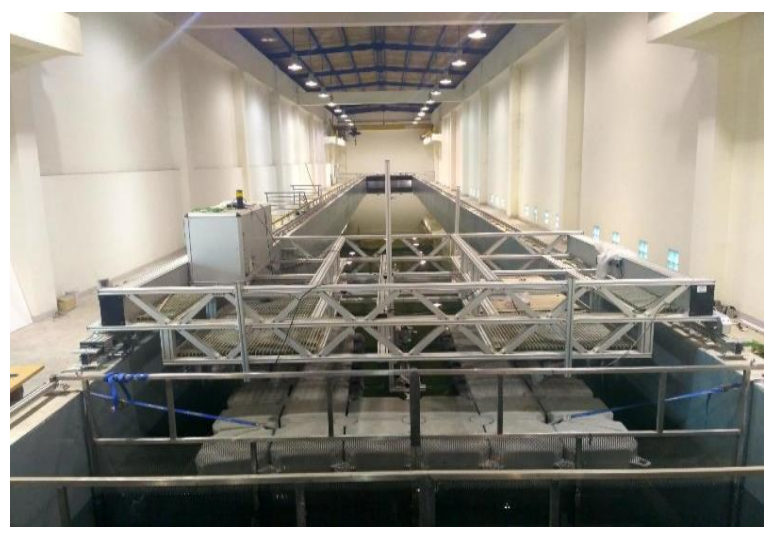

Figure 1. The towing tank facility, Naval Architecture Department, Faculty of Engineering, Hasanuddin University

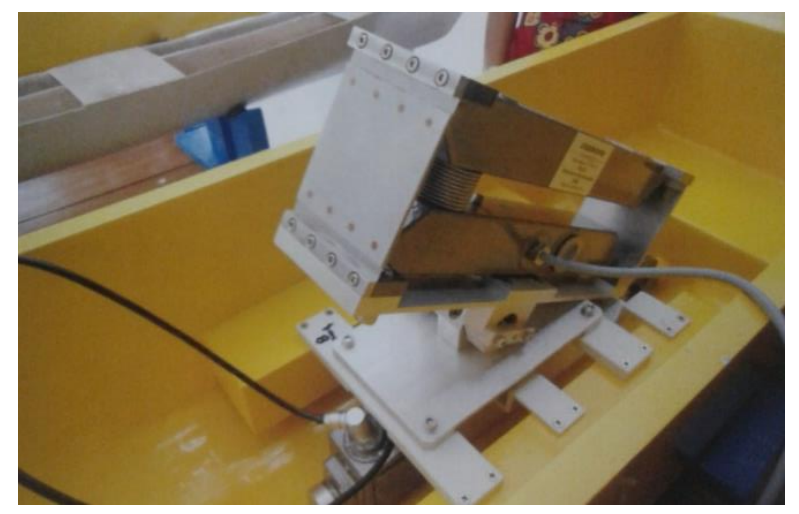

Figure 2. The resistance dynamometer R35E as attached on model

Table 1. The main dimensions of actual ships and ship models

\begin{tabular}{cccccccccc}
\hline & \multicolumn{7}{c}{ Actual Ship (AS) and Model (M) } \\
\cline { 2 - 9 } Dimension & \multicolumn{2}{c}{ B5L10 } & \multicolumn{2}{c}{ B5L11 } & \multicolumn{2}{c}{ B5L12 } & \multicolumn{2}{c}{ B5L13 } \\
\cline { 2 - 10 } & AS & M & AS & M & AS & M & AS & M \\
\hline Lbp (m) & 58.56 & 1.36 & 64.44 & 1.50 & 70.33 & 1.64 & 76.22 & 1.77 \\
B (m) & 17.10 & 0.39 & 17.10 & 0.39 & 17.10 & 0.39 & 17.10 & 0.39 \\
H (m) & 5.08 & 0.12 & 5.08 & 0.12 & 5.08 & 0.12 & 5.08 & 0.12 \\
T (m) & 3.37 & 0.08 & 3.37 & 0.08 & 3.37 & 0.08 & 3.37 & 0.08 \\
\hline
\end{tabular}




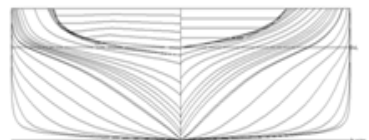

B5L10

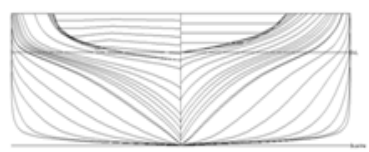

B5L12

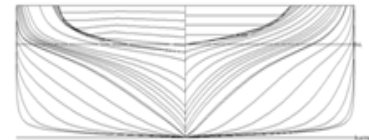

B5L11

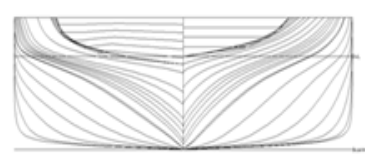

B5L13
Figure 3. The body lines plan of the actual ships
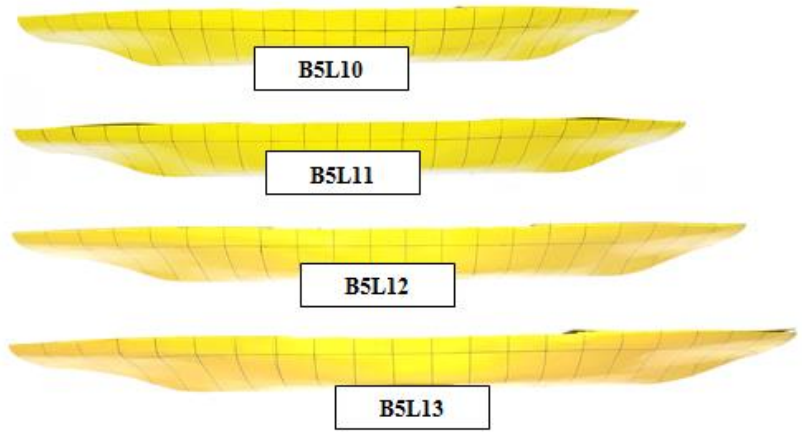

Figure 4. The ship models B5L10, B5L11, B5L12, and B5L13

The resistance data were collected three times for each model speed and then the resistance values which are analyzed further were obtained in stable condition. Here, the total resistance has been analyzed further by using ITTC 1957 method [12] which is divided into two components which are friction resistance and residuary resistance. This is done to predict the magnitude dominance of friction resistance or cause of increasing speed by lengthening.

The lengthening the Ro-Ro ferry is described on increase length size as provided in Table 1 where the lengthening shows an increment of every 5.88 meters. In addition, it could be indicated by a non-dimensional parameter as well by the ratio of ship length and the cubed root of displaced volume $L b p / \nabla^{1 / 3}$. Therefore, a relation between total resistance $R T$ and lengthening ship $L b p / \nabla^{1 / 3}$ could be interpreted further.

Moreover, the influence of speed on loading capacity of Ro-Ro ferry has been interpreted as well by using a graph of the relation between ship speed $V$ and the ratio of total resistance with load capacity $R t / S_{U K}$ where $S_{U K}$ is defined by loading capacity. The loading capacity $S_{U K}$ of the Ro-Ro ferries is based on the number of carried cars in car deck.

\section{Results and Discussions}

The resistance experiment by using Ro-Ro ferries models in towing tank was successfully conducted. The models were adjusted to similar geometry and kinematics characteristics with the actual ship dimensions. This means that the models have the same hydrodynamics caracteristics with the actual ship. Therefore, the following furher explanations concerning on model experiment results are indicated the same with the actual ship. An example time history of resistance which was

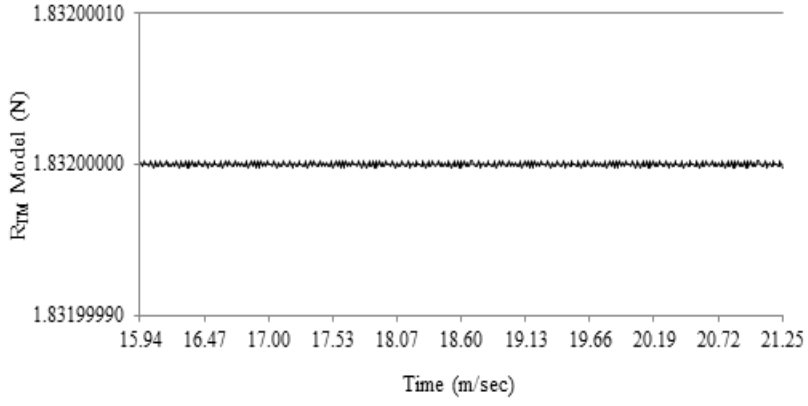

Figure 5. Time history of resistance, model B5L10, speed $0.942 \mathrm{~m} / \mathrm{sec}$

Table 2 . The total resistance in increased speed of every model

\begin{tabular}{ccccc}
\hline \multirow{2}{*}{ Vm $(\mathbf{m} / \mathbf{s e c})$} & \multicolumn{4}{c}{$\mathbf{R}_{\text {TM }}$ Model $(\mathbf{N})$} \\
\cline { 2 - 5 } & B5L10 & B5L11 & B5L12 & B5L13 \\
\hline 0.314 & 0.231 & 0.232 & 0.257 & 0.270 \\
0.628 & 0.803 & 0.806 & 0.898 & 0.945 \\
0.942 & 1.833 & 1.807 & 1.997 & 2.084 \\
1.256 & 4.109 & 3.881 & 4.232 & 4.311 \\
1.570 & 10.687 & 9.485 & 8.838 & 8.179 \\
\hline
\end{tabular}

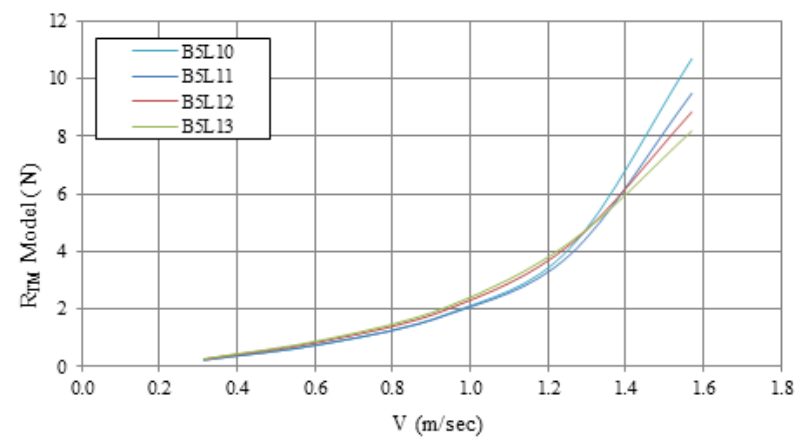

Figure 6. Total resistance of all ship models in increasing speed obtained by conducting the experiment

obtained from the conducted experiment is shown in Fig. 5 . Then, the overall total resistance in increased speed for all models is provided in Table 2.

Based on Fig. 5, the resistance value $R_{T M}$ shows quite stable data in a certain time and it shows also a small difference during the towing model process. The graph of the total resistance in increased speed $V m$ for all models is shown in Fig. 6 and it tends to increase in increasing speed. However, small length model which is B5L10 has the biggest resistance in speed $V m>1.29 \mathrm{~m} / \mathrm{sec}$ compared with others and then the big length B5L13 shows the lowest resistance in speed $V m>1.36 \mathrm{~m} / \mathrm{sec}$. Moreover, the resistance significantly increases when speed reaches more than $1.20 \mathrm{~m} / \mathrm{sec}$ for all models. This means that the effective speed of all ships are required properly where the increment of resistance is not significantly high or overestimated for every increasing speed.

Meanwhile, this total resistance would be derived and decomposed into two components such as friction resistance $R_{F}$ and residuary resistance $R_{R}$. The overall friction resistance and residuary resistance of all models in increased speed are provided in Table 3 and 4 respectively. 
Table 3. The friction resistance in increased speed for all models

\begin{tabular}{ccccc}
\hline \multirow{2}{*}{$\mathbf{V m}(\mathbf{m} / \mathbf{s e c})$} & \multicolumn{4}{c}{ Friction Resistance (N) } \\
\cline { 2 - 5 } & B5L10 & B5L11 & B5L12 & B5L13 \\
\hline 0.314 & 0.164 & 0.177 & 0.188 & 0.200 \\
0.628 & 0.559 & 0.602 & 0.643 & 0.684 \\
0.942 & 1.151 & 1.240 & 1.325 & 1.411 \\
1.256 & 1.925 & 2.076 & 2.219 & 2.365 \\
1.570 & 2.873 & 3.099 & 3.315 & 3.533 \\
\hline \multicolumn{5}{c}{ Table 4. The Residuary resisance in increased speed for all models } \\
\hline \multicolumn{5}{c}{ Residuary Resistance (N) } \\
Vm (m/sec) & B5L10 & B5L11 & B5L12 & B5L13 \\
\cline { 2 - 5 }$(\mathbf{N})$ & $\mathbf{( N )})$ & $(\mathbf{N})$ \\
\hline 0.314 & 0.067 & 0.055 & 0.069 & 0.070 \\
0.628 & 0.243 & 0.203 & 0.254 & 0.260 \\
0.942 & 0.681 & 0.566 & 0.671 & 0.672 \\
1.256 & 2.181 & 1.802 & 2.010 & 1.943 \\
1.570 & 7.807 & 6.380 & 5.517 & 4.641 \\
\hline \multicolumn{5}{c}{}
\end{tabular}

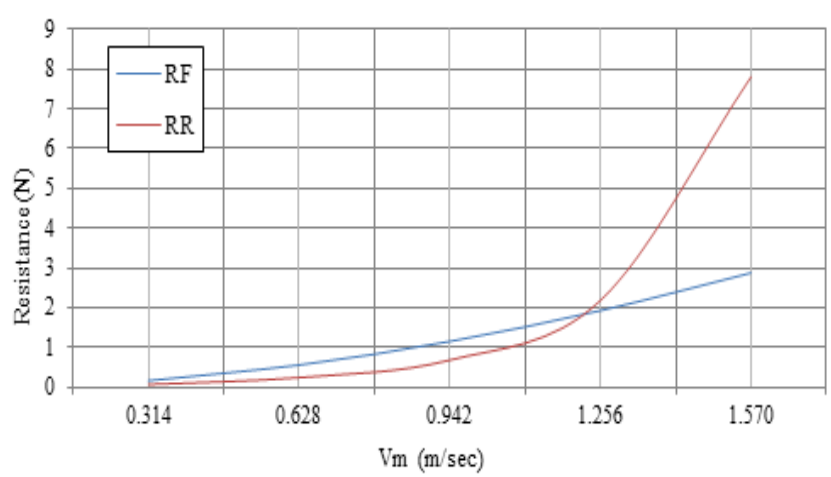

Figure 7. The friction resistance and the residuary resistance in increased speed for the model B5L10

Table 5. The composition of Friction and Residuary resistances in total resistance for each Ro-Ro ferry and increased speed

\begin{tabular}{cccccccccc}
\hline \multirow{2}{*}{$\begin{array}{c}\mathrm{V}_{\mathrm{M}} \\
(\mathrm{m} / \mathrm{sec})\end{array}$} & \multicolumn{2}{c}{ B5L10 } & \multicolumn{2}{c}{ B5L11 } & $\mathrm{R}$ & $\mathrm{2}$ & $\mathrm{B} 5 \mathrm{~L} 12$ & \multicolumn{2}{c}{ B5L13 } \\
& $(\%)$ & $(\%)$ & $\begin{array}{c}\mathrm{RF} \\
(\%)\end{array}$ & $\begin{array}{c}\mathrm{RR} \\
(\%)\end{array}$ & $\begin{array}{c}\mathrm{RF} \\
(\%)\end{array}$ & $\begin{array}{c}\mathrm{RR} \\
(\%)\end{array}$ & $\begin{array}{c}\mathrm{RF} \\
(\%)\end{array}$ & $\begin{array}{c}\mathrm{RR} \\
(\%)\end{array}$ \\
\hline 0.314 & 71.14 & 28.86 & 76.12 & 23.84 & 73.24 & 26.72 & 74.08 & 25.88 \\
0.628 & 69.13 & 30.87 & 74.20 & 25.80 & 70.98 & 29.02 & 71.77 & 28.23 \\
0.942 & 57.45 & 42.55 & 63.74 & 36.26 & 62.09 & 37.91 & 63.85 & 36.15 \\
1.256 & 34.07 & 65.93 & 40.33 & 59.67 & 40.05 & 59.95 & 42.86 & 57.14 \\
1.570 & 14.44 & 85.55 & 18.29 & 81.71 & 23.82 & 76.18 & 30.24 & 69.76 \\
\hline
\end{tabular}

Table 6. The lengthening Ro-Ro ferry $\mathrm{Lbp} / \nabla^{1 / 3}$ for each ship

\begin{tabular}{ccccc}
\hline $\begin{array}{c}\text { Dimension/ } \\
\text { non dimension }\end{array}$ & B5L10 & B5L11 & B5L12 & B5L13 \\
\hline $\mathrm{Lbp}(\mathrm{m})$ & 1.36 & 1.50 & 1.64 & 1.77 \\
$\mathrm{~V}\left(\mathrm{~m}^{3}\right)$ & 0.024 & 0.026 & 0.029 & 0.031 \\
$\mathrm{~L} / \mathrm{V}^{1 / 3}$ & 4.72 & 5.06 & 5.32 & 5.64 \\
\hline
\end{tabular}

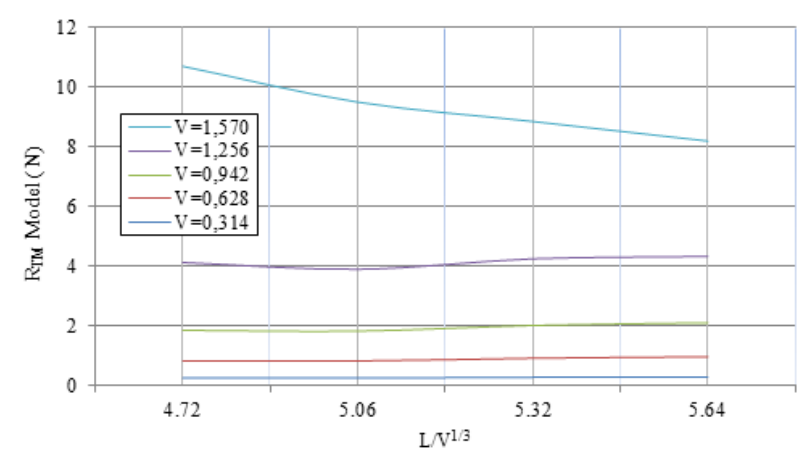

Figure 8 . The total resistance in increased speed by lengthening Ro-Ro ferry $\mathrm{Lbp} / \nabla^{1 / 3}$

One example of graph of friction resistance and residuary resistance in increased speed is shown in Fig. 7. The friction resistance has higher proportion compared with the residuary resistance into total resistance when $V m<1.216 \mathrm{~m} / \mathrm{sec}$. However, the friction resistance is lower in $V m>1.216 \mathrm{~m} / \mathrm{sec}$. The friction resistance tends to increase relatively linear and the residuary resistance is in exponential growth. The composition of friction and residuary resistances in total resistance for each Ro-Ro ferry and increased speed is shown in Table 5 where the lengthening affects on bigger residuary resistance when in high speed $\mathrm{V} \geq 1.256 \mathrm{~m} / \mathrm{sec}$. This means that the high residuary resistance could be avoided for the lengthening ship and then it could be considered to determine an effective speed.

On the other hand, the lengthening Ro-Ro ferry $L b p / \nabla^{1 / 3}$ for each B5L10, B5L11, B5L12, and B5L13 is shown in Table 6 . The lengthening affects total resistance where it is relatively the same in small speeds which are in 0.314 and $0.628 \mathrm{~m} / \mathrm{sec}$ as shown in Fig. 8. Moreover, the total resistance increases small in speeds 0.942 and $1.256 \mathrm{~m} / \mathrm{sec}$. Contrary, it decreases significantly in speed of $1.570 \mathrm{~m} / \mathrm{sec}$ by leghtening ship. The increase of total resistance is affected by residual resistance at high speeds for the ship that have a small length. Therefore by lengthening the ship, it could reduce total resistance, especially in the residuary resistance. However, the effective speed for lengthening Ro-Ro ferry $\mathrm{Lbp} / \mathrm{V}^{1 / 3}$ should consider the loading capacity of carried car $S U K$ that is explained further.

Meanwhile, the lengthening Ro-Ro ferry should consider also the loading capacity of carried car associated with effective speed. The number of carried cars for every Ro-Ro ferry is shown in Table 7. Here, the ratio of total resistance with a loading capacity of carried car $R T / S_{U K}$ is a parameter that could show a relation between increased speeds as shown in Fig. 9. Based on the figure, the loading capacity of carried car $S_{U K}$ could be increased by lengthening which affects on increasing speed as well. Therefore, it seems that the ratio of total resistance with loading capacity of carried car $R t / S_{U K}$ increases in increasing speed for all ships. 
Table 7. The number of carried cars for every Ro-Ro ferry

\begin{tabular}{cccc}
\hline \multicolumn{4}{c}{ Loading Capacity of Carried Car $\left(\mathrm{S}_{\mathrm{UK}}\right)$} \\
\hline B5L10 & B5L11 & B5L12 & B5L13 \\
\hline 50 & 55 & 60 & 65 \\
\hline
\end{tabular}

Table 8 . The speed of each ship in the same $\mathrm{R}_{\mathrm{TM} /} \mathrm{S}_{\mathrm{UK}}$

\begin{tabular}{ccccc}
\hline \multirow{2}{*}{$\mathrm{R}_{\mathrm{TM} / \mathrm{S}}$} & \multicolumn{4}{c}{ Speed $(\mathrm{m} / \mathrm{sec})$} \\
\cline { 2 - 5 } & B5L10 & B5L11 & B5L12 & B5L13 \\
\hline 0.03 & 0.914 & 0.945 & 0.986 & 1.020 \\
0.04 & 1.011 & 1.046 & 1.090 & 1.128 \\
0.05 & 1.086 & 1.124 & 1.172 & 1.212 \\
0.06 & 1.148 & 1.188 & 1.238 & 1.281 \\
0.07 & 1.200 & 1.241 & 1.294 & 1.339 \\
\hline
\end{tabular}

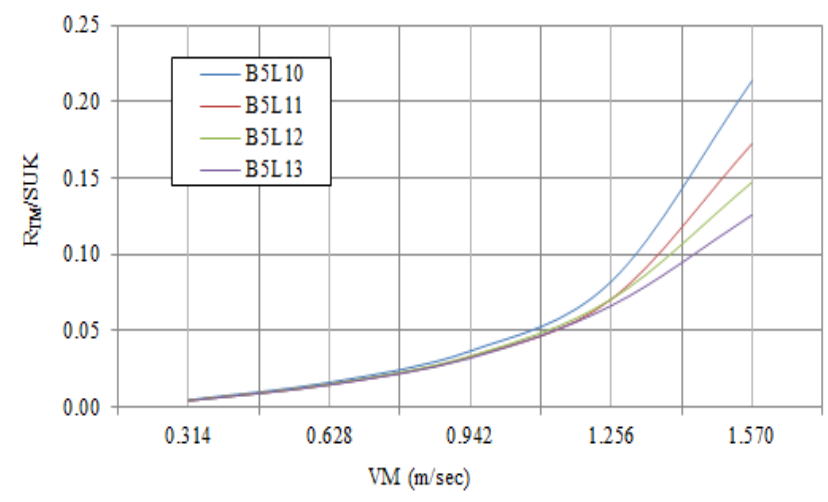

Figure 9. The ratio of total resistance with loading capacity of carried car in increased speeds

The ratio of total resistance with loading capacity of carried car increases gently in speed range $V$ from 0.314 $\mathrm{m} / \mathrm{sec}$ to $1.212 \mathrm{~m} / \mathrm{sec}$ and it increases significant highly in a small range of increased speed at speed $>1.256$. Table 8 provides the speed of each ship in the same $R t / S_{U K}$ where this shows only until 0.07 . This could be as consideration to determine an effective speed of Ro-Ro ferry taking into account the loading capacity of carried car. Therefore, the effective speed for each ship is given at the same $R t / S_{U K} 0.05$ where B5L10 is at $1.087 \mathrm{~m} / \mathrm{sec}$, B5L11 at $1.124 \mathrm{~m} / \mathrm{sec}$, B5L12 at $1.172 \mathrm{~m} / \mathrm{sec}$, and B5L13 at $1.212 \mathrm{~m} / \mathrm{sec}$. This speed also could be converted to speed for actual ship dimension where B5L10 is about 13.85 knot, B5L11 14.33 knot, B5L12 14.94 knot, and B5L13 15.45 knot, respectively.

\section{Conclusions}

The resistance experiment by using Ro-Ro ferries models in towing tank was successfully conducted. The models have the same hydrodynamics caracteristics with the actual ship. The increase in total resistance is caused by higher residual resistance at high speeds. This is experienced by small length size therefore by lengthening the ship it could reduce total resistance at the same speed especially the residuary resistance.

In additions, the effective speed for actual ships dimension in the same $R t / S_{U K} 0.05$ i.e. B5L10 is about 13.85 knot, B5L11 14.33 knot, B5L12 14.94 knot, and B5L13 15.45 knot respectively. Therefore, the lengthening Ro-Ro ferry could be simulated in the preliminary ship design or analized in conversion ship but it should consider ship resistance, speed, and loading capacity of carried car for enhancing ferries business and safety.

\section{Acknowledgement}

We are very grateful to the undergraduate students namely Sahudin, Ardedi Yusuf, Bayu Anggara, Ardian, Abdul Wahid, Muh. Riky Adhitama, Muh. Taslim, Adi Rais Saputra who have helped in conducting the experiment.

\section{References}

[1] Schneekluth, H., Bertram, V. (1998). Ship Design for Efficiency and Economy. $2^{\text {nd }}$ Edition, Butterworth-Heinemann.

[2] IMO, (1997). IMO and Ro-Ro Safety. Focus on IMO

[3] Levander, K., Yard, K.M. (2001). EUROCONFERENCE; Passenger Ship Desing, Construction, Operation and Safety, Crete, Greece, pp. 45-62.

[4] Krueger, S., Yard, F.S.G. (2001). Competitive RoRo-Ships by First Principle Design Tools. EUROCONFERENCE; Passenger Ship Desing, Construction, Operation and Safety, Crete, Greece, pp. 6372.

[5] Kanerva, M., Poylio, E., Lindqvist, G. (2001). From Handy Size up to Cruise Ferries, Elements Required to Design and Build Successful Configuration. EUROCONFERENCE; Passenger Ship Desing, Construction, Operation and Safety, Crete, Greece, pp. 83112 .

[6] SAFER EURORO (2003). Design for Safety: An Integrated Approach to Safe European Ro-Ro Ferry Design. Available at http://research.dnv.com/skj/safereuroro/safer_euroro_1_final.pdf

[7] Zaraphonitis, G., Boulougouris, E., Papanikolaou, A. (2003). An Integrated Optimisation Procedure for the Design of Ro-Ro Passenger Ships of Enhanced Safety and Efficiency. Proc. IMDC 03, Athens, Vol. I, pp. 313-324.

[8] Boulougouris, E.K., Papanikolaou, A.D., Zaraphonitis, G. (2004) Optimization of Arrangements of Ro-Ro Passenger Ship with Genetic Algorithms. Ship Technology Research, 51(3):99-105.

[9] Richards, J.S., Reinholz, O. (2011). Hydrodynamic Trends in Ferry Design. The 11th International Conference on Fast Sea Transportation FAST 2011, Honolulu, Hawaii, September 2011.

[10]Kristensen, H.O.H., Hagemeister, C. (2012). Environmental Performance Evaluation of Ro-Ro Passenger Feery Transportation. Danish Information Paper for the Work in the MEPC committee under the International Maritime Organisation, IMO, London.

[11] Asri, S., Pallu, M.S., Thaha, M.A., Misliah. (2015). Model Design of Inter-Island Ships Base on Transport Demand and Port Facility. International Journal of Engineering Research \& Technology, Vol. 4(12), pp. 643-651.

[12]ITTC (2002). Recommended Procedures, Resistance Uncertainty Analysis, Example for Resistance Test, Specialist Committee of 23rd ITTC. 